\title{
Accuracy of Ultrasonogram in Diagnosis of Acute Appendicitis
}

\author{
Perveen $\mathrm{R}^{1}$, Islam AFMS ${ }^{2}$, Rahman $\mathrm{H}^{3}$, Khan $\mathrm{RP}^{4}$
}

\begin{abstract}
Introduction: Acute appendicitis is one of the most common causes of abdominal pain of adult patients referred to the emergency department. Despite its prevalence, the diagnosis of appendicitis can be elusive and fraught with pitfalls because of the absence of a pathognomonic sign or symptom and the poor predictive value of laboratory testing. So following the significant advances in accuracy, ultrasonography has become an important part of the modern work-up of acute appendicitis.
\end{abstract}

Objective: To evaluate the role and accuracy of ultrasonography in the diagnosis of acute appendicitis.

Materials and Methods: A total number of 110 cases ( 65 men and 45 women), with clinical suspicion of appendicitis, were subjected to abdominal ultrasonographic examination. All ultrasonographic positive cases and a few of ultrasonographic negative cases were subjected to operative intervention. The accuracy of ultrasonography in the diagnosis of appendicitis was compared with the clinical diagnosis, operative findings and histopathological examination reports. The statistical analysis was done by using SPSS10.

Results: Among 110 cases, 77 cases were sonographically positive for appendicitis and 5 cases were appendicular masses. The cardinal signs were right lower abdominal tenderness, rebound tenderness and positive Rovsing's sign. The specificity of Ultrasound was $74.28 \%$, sensitivity $90.66 \%$, positive predictive value $88.31 \%$, negative predictive value $78.79 \%$ and accuracy was $85.45 \%$ in the diagnosis of acute appendicitis.

\section{Conclusion}

So far the cost reduction of treatment and negative laparotomies are concerned, the ultrasonography is still an useful tool in the diagnosis of appendicitis in spite of more recent investigations like CT abdomen and Laparoscopy.

Key-words: Acute Appendicitis, Ultrasonography, Accuracy of Diagnosis, Sensitivity, Specificity.

\section{Introduction}

Abdominal ultrasonography (USG) has a definitive role in the diagnosis of acute appendicitis because it establishes an alternative diagnosis in patient with acute right lower abdominal pain and reduces the number of negative laparotomies ${ }^{1}$. Delay in the diagnosis and surgery in some atypical cases of appendicitis may result in perforation. This occurs in $17-39 \%$ of patients with appendicitis. The elderly and very young are at a higher risk ${ }^{2}$. Acute appendicitis is still the most common indicator to emergency abdominal surgery. The clinical diagnosis of appendicitis is difficult in a few cases. Approximately $20.33 \%$ of patients will present atypically ${ }^{1,2,3}$. The inflamed appendix is seen as a blind ended tubular structure with laminated wall arising from the base of cecum. Puylaert reported the sensitivity of $89 \%$ and specificity $100 \%$ in the diagnosis of acute appendicitis by ultrasonography ${ }^{4,6}$. However the diagnosis is still based on clinical features. The aim of this study was to evaluate the role of ultrasonography to find out its accuracy to diagnose the appendicitis by comparing with clinical assessment and histopathological reports.

1. Dr Rosy Perveen, MBBS, FCPS, Assistant Professor of Radiology and Imaging, Medical College for Women and Hospital (MCWH), Uttara, Dhaka 2. Dr AFMS Islam, MBBS, DMRD, Associate Professor and Head, Department of Radiology and Imaging, MCWH, Uttara, Dhaka 3. Brig Gen Habibur Rahman (Retd), MBBS, FCPS, Professor in Surgery, Nightangle Medical College, Savar, Dhaka 4. Dr Ruksana P Khan, MBBS, DNM, Sonologist, MCWH, Uttara, Dhaka. 


\section{Materials and Methods}

This observational study was carried out in the department of Radiology and Imaging in collaboration with the department of Surgery in MCWH at Uttara, Dhaka and Catharsis Hospital, Pubail, Dhaka over a period of 2 years from May 2014 to April 2016. A total of 110 patients (65 men and 45 women, age range from 10 years to 65 years) who presented with pain in the right lower abdomen, in whom acute appendicitis was suspected basing on clinical features, were subjected to abdominal USG examination.

\section{Inclusion Criteria:}

- Male and female patients with age group of 10 to 65 years.

- Pain in right iliac fossa.

- Fever.

- Increased leucocytes count.

- Mass in right iliac fossa.

- Patients with recurrent appendicitis were also included.

\section{Exclusion Criteria:}

- Patients below 10 and above 65 years of age.

- History of previous laparotomy.

- Chronic infectious disease like ileocecal tuberculosis.

Carcinoid tumors and other neoplastic lesions of the appendix.

- Patients with 3rd trimester of pregnancy.

\section{Sonographic Criteria:}

The following accepted criteria were considered for the diagnosis of an inflamed appendix.

a. A peristaltic non compressive appendix as a blind ending tubular structure.

b. Diffuse hypoechogenecity (associated with a higher incidence of perforation)

c. Target appearance of $\geq 6 \mathrm{~mm}$ (6 millimeters) in the total diameter on cross section (81\%) in aximal mural wall thickness $\geq 2 \mathrm{~mm}$.

d. Localized periappendicular fluid collection.

e. Lumen may be distended with an echoic/ hyper echoic material.

f. Visualization of appendicolith

g. Free pelvic fluid.

h. Prominent hyperechoic mesoappendix/ pericaecal fat.

\section{The criteria of Negativity:}

Negative appendix was defined as normal looking appendix on operation and absence of acute inflammation on histopathology. All cases were sent for histopathology and the ones in which histopathological examination (HPE) was negative, were considered as true negatives.

\section{Results}

It has been shown that all of the patients included in the study had history of abdominal pain which was considered to be of strong clinical suspicion of acute appendicitis. Tenderness over right iliac fossa (RIF) was the most common sign elicited in all 110 cases $(100 \%)$. Migration of pain to RIF was found in 80 $(72.72 \%)$, vomiting was found in $70(63.63 \%)$ cases, rebound tenderness in 85 (77.27\%), Rovsing's sign in $49(44.54 \%)$ and fever in $45(40.90 \%)$ cases (Table-I).

Table-l: Clinical signs and symptoms

\begin{tabular}{|l|c|c}
\hline Symptoms & Cases(n) & \\
\hline Pain in abdomen & 110 & \\
\hline Migration of pain & 80 & 7 \\
\hline Fever & 45 & 4 \\
\hline Vomiting & 70 & 6 \\
\hline Diarrhoea & 9 & 8 \\
\hline Dysuria & 6 & 5 \\
\hline Sign & 110 & \\
\hline RlF Tenderness & 85 & 7 \\
\hline Rebound tenderness & 27 & 2 \\
\hline Guarding & 55 & \\
\hline Tachycardia & 49 & 4 \\
\hline Rovsing's sign & 80 & 7 \\
\hline Leukocytosis & 90 & 8 \\
\hline Neutrophilia & 18 & 1 \\
\hline Pus cell and RBC in urine &
\end{tabular}

Total white cell count rose significantly in $72.72 \%$ in our patients. This result was comparable to the study done by Lewis et $\mathrm{al}^{14}$.The outer diameter of the appendix was greater than $6 \mathrm{~mm}$ in all 77 cases $(70 \%)$. It is lower than the criteria letdown by Jeffrey et $\mathrm{al}^{16}$.

Table-II: USG diagnosis of RIF pain $(n=110)$

\begin{tabular}{|l|c|l}
\hline Pathology & Cases(n) & \\
\hline Acute appendicitis & 77 & \\
\hline Right ureteric colic & 03 & \\
\hline Pelvic inflammatory disease & 06 & \\
\hline Ovarian cyst & 08 & \\
\hline Appendicular mass & 04 & \\
\hline Ectopic pregnancy & 05 & \\
\hline Inconclusive findings & 07 & \\
\hline
\end{tabular}


All 77 cases which were sonologically positive underwent operative treatment and out of these 77 cases, 68 cases were histopathologically (HPE) positive and 09 cases were HPE negative (Table-III).

\begin{tabular}{l|c}
\multicolumn{2}{|c}{ Histopathological diagnosis } \\
\hline logy Diagnosis & Cases(n) \\
\hline ndicitis among USG positive cases & 68 \\
\hline ndicitis among USG negative cases & 07 \\
\hline pendicitis & 05 \\
\hline Hyperplasia & 08 \\
\hline
\end{tabular}

The sonologically negative cases were managed conservatively but in this group of 33 cases due to the persistence of symptoms and or surgeon's suspicion 11 cases were operated upon. Out of these 11 cases 07 were HPE positive (Table-IV) Lewis et al noted that pain abdomen which localized in right lower quadrant contributed to the maximum number of patients which was similar to our study

\begin{tabular}{l|c}
\multicolumn{2}{|c}{ Correlation of HPE diagnosis with HPE } \\
\hline umber of cases & $\mathbf{1 1 0}$ \\
\hline sitive & 77 \\
gative & 33 \\
sitive & 68 \\
gative & 9 \\
\hline gative Case Operated & 11 \\
sitive & 07 \\
gative & 04 \\
\hline S & \\
\hline ases of USG & 110 \\
\hline sitive & 77 \\
\hline sitive & 68 \\
\hline sitive & 68 \\
\hline gative & 26 \\
\hline ositive & 09 \\
\hline egative & 07 \\
\hline
\end{tabular}

In this study, tenderness in right lower fossa was seen in $100 \%$ cases whereas rebound tenderness at McBurney's point was noted in $92 \%$ which is similar to the findings shown by Taura et $\mathrm{al}^{15}$. Observation shows that the overall sensitivity was $90.66 \%$, specificity was $74.28 \%$, positive predictive value (PPV) $88.31 \%$, negative predictive value (NPV) $78.79 \%$ and diagnostic accuracy $85.45 \%$.

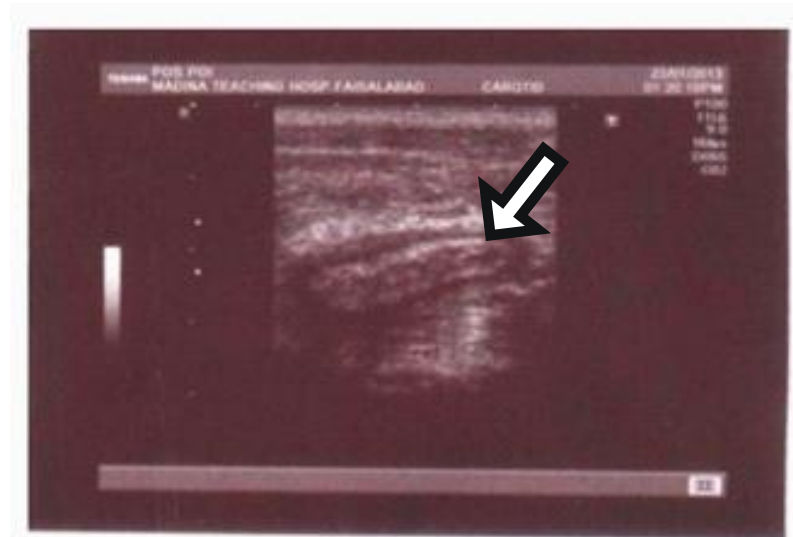

Fig-1: Gray scale image of inflamed, noncompressible appendix as blind ended tubula structure with cross section diameter of $7.9 \mathrm{~mm}$ and wall thickness of $2.1 \mathrm{~mm}$.

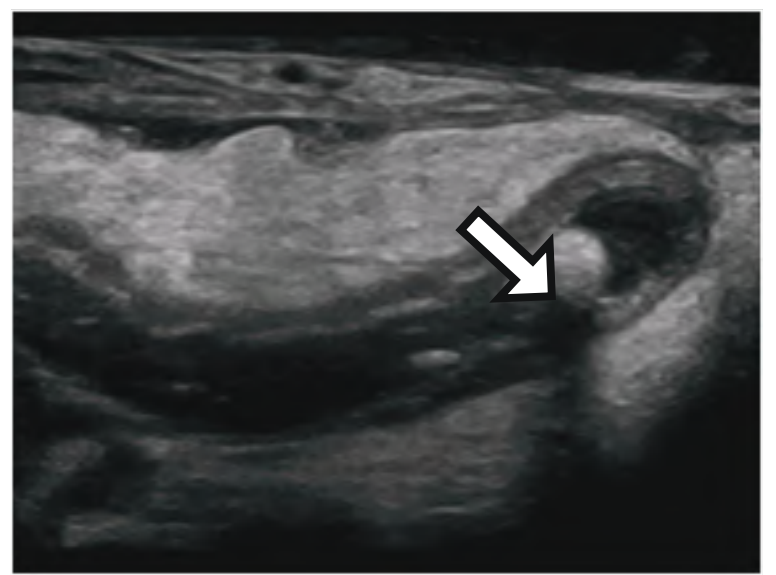

Fig-2: Appendicolith in Ultrasonogram as bright echogenic focus

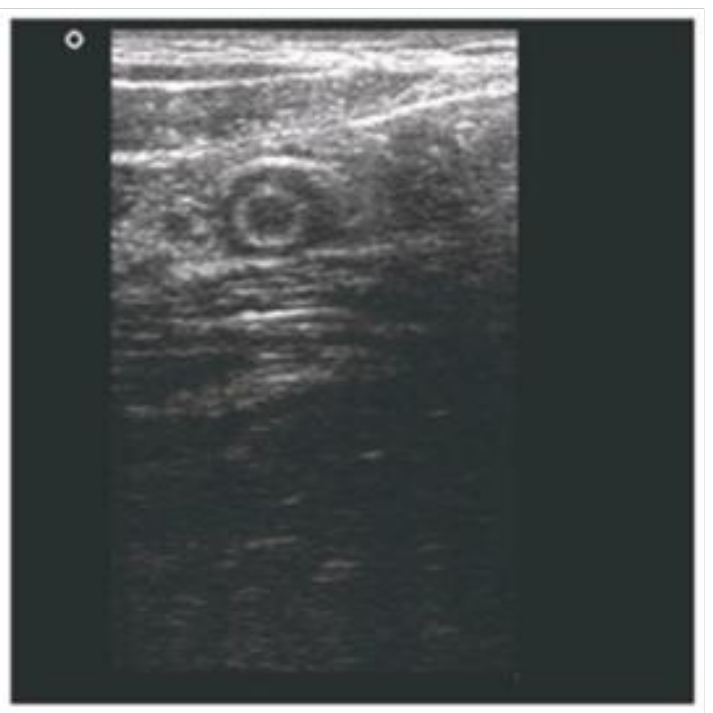

Fig-3: Target sign with inflamed appendix on USG. 


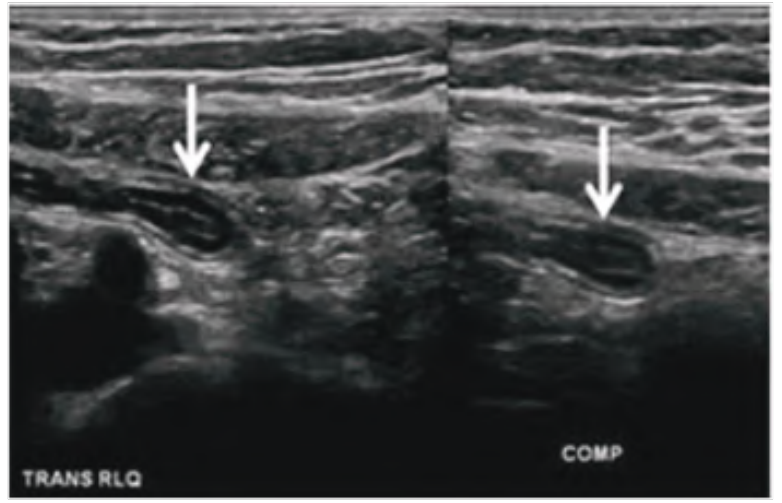

Fig-4: Inflamed appendix with peri appendicular fluid collection.

\section{Discussion}

Ultrasonography (USG) is a widely available and inexpensive modality of investigation that has the potential for highly accurate imaging in patients with suspected acute appendicitis. Diagnosis of acute appendicitis is not always straightforward. Sometimes the presentation of the disease is so atypical that even the most experienced surgeon may remove normal appendix or sit on the perforated one ${ }^{8-9}$. The advantage of USG over computed tomography (CT) is that it allows precise correlation of the USG findings with the area of maximum tenderness or with a palpable mass. The PPV in this study is $88.31 \%$ which is relatively low compared with other studies $^{10-11}$ and can be explained by the study design. This study mainly focused on the screening value of sonography with the sonograms interpreted in a manner to avoid missing any cases with positive findings. Therefore, subtle but non-specific signs that might have indicated acute appendicitis, such as fluids in right paracolic gutter, were interpreted as positive results. These results are comparable to a Korean meta-analysis on the role of USG in the diagnosis of acute appendicitis which shows sensitivity and specificity $86.7 \%$ and $90.0 \%$ respectively ${ }^{12-13}$.

This study is compared with study of Tauro et al15, Jo Shi et $\left.a\right|^{17} \mid d a$ chan et $\left.a\right|^{18}$ and Rioux et al ${ }^{19}$ which has been shown in Table-VI whose sensitivity values varied from 83 to $90 \%$ and specificity ranges from 88.09 to $95 \%$. In this study overall accuracy of sonography was $85.45 \%$ and the results were comparable to the studies of Tarzan $z$ et $a^{20}{ }^{20}$, Hahn et $\mathrm{al}^{21}$ and Skanne et $\mathrm{al}^{22}$.
The Table-V summarizes the results of our study compared with the results of similar studies in different parts of the world.

Table-V: Validity Test $(n=110)$

\begin{tabular}{|l|c|c|c|c|c|}
\hline Reference & Sensitivity & Specificity & PPV & NPV & Avg \\
\hline Present Study & 90.66 & 74.28 & 88.31 & 78.79 & 85.45 \\
\hline Tauro LF et al & 91.37 & 88.09 & 91.37 & 88.09 & 90 \\
\hline Chan et al & 83.00 & 95.00 & 86.00 & 94.00 & 92 \\
\hline Jo Shi et al & 96.00 & 93.00 & 98.00 & 88.00 & 95 \\
\hline Rioux et al & 93.00 & 94.00 & 86.00 & 98.00 & 94 \\
\hline
\end{tabular}

\section{Limitations and Drawbacks of the study}

There are certain drawbacks in using ultrasonography for diagnosing acute appendicitis. The foremost important is the experience of the sonologist as the procedure is highly operator dependent. Considering the cost factor of the contrast CT study, it was not included for the accurate diagnosis of dubious cases.

\section{Conclusion}

The gold standard for the diagnosis of appendicitis still remains pathologic confirmation after appendectomy. The accuracy of USG in this aspect is extremely variable due to many reasons, including lack of operator skill, increased bowel gas content, obesity, anatomic variants and limitations to explore patients with previous laparotomies. It is inexpensive, safe and widely available. Diagnostic accuracy is reported to range from $71 \%$ to $97(\%)^{21-22}$. So USG remains our first line method in the evaluation of patients referred with clinically suspected acute appendicitis. Nevertheless, due to variable diagnostic accuracy, individual skill is requested not only to perform successful examination but also to warrant computed tomography (CT) for equivocal cases to reduce the rate of fatal consequences like perforations.

\section{References}

1. Jeffrey RB Jr, Laing FC, Levis FR. Acute appendicitis, high resolution real-time ultrasound findings. Radiology 1987; 163:11-4.

2. Deutch AA, Shani V, Reiss R. Are some appendectomies unnecessary? An analysis of 319 white appendices, JR Coll Surg Edin 1983; 28:35-40. 
3. Jess P, Bjeraegaard B, Brynitz $S$ et al. Acute appendicitis: Prospective trialcocermiry diagnost accuracy and complication. Am J Surg 1987; 141:232-4.

4. Balthezar EJ et al. Acute appendicitis: CT and ultrasound correlation in 100 patients. Radiology 1994; 190:31-5.

5. Lewis FR, Itol croft JW, Boey J et al. Appendicitis: A clinical review of diagnosis and treatment in 1000 cases. Azeh surg 1975; 110:677-84.

6. Berry J Jr, Malt RA. Appendicitis near its century. Ann Surg 1984 Nov; 200(5):567-75.

7. Puylaert JB. Acute Appendicitis: US evaluation using graded compression. Radiology 1986; 158(2):355-60.

8. Hale DA, Molloy M, Pearl RH et al. Appendectomy: A contemporary appraised. Ann Surg 1997; 225(3):252-61.

9. Zielke A, Hasse C, Sitter H et al. Influence of ultrasound on clinical decision making in acute appendicitis: $A$ prospective study. Eur J surg 1998; 164:201-9.

10. Wilson B; Cole JC, Nipper ML et al. Computed tomography and ultrasonography in the diagnosis of appendicitis. When are they indicated? Arch surg 2001; 136:670-5.

11. Rao PM, Boland GW. Imaging of acute right lower abdominal quadrant pain. clinical Radiology 1998; 53:639-49.

12. Yu SH, Kim CB, Park JW et al. Ultrasonography in the diagnosis of appendicitis: Evaluation by meta-analysis. Korean J Radiol 2005 Oct-Dec; 6(4):267-77.
13. Asefa G, Mesret S, Nugussle Y. The role of ultrasound in diagnosis acute appendicitis. Ethiol med KJ 2006; 44:67-74.

14. Lewis FB, Holcroft Boey J, Dumphy EA, critical Review of diagnosis and treatment in thousand case. Arch of surgery, 1975; 110:677-84.

15. Tauro Lf, premanand TS, Aithala PS et al. Ultrasonography is still A useful diagnostic tool in Acute Appendicitis. Journal of clinical \& Diagnostic Research 2009 oct; 3:1731-36.

16. Jeffery RB Jr, Laing FC, Townsend RR. Acute Appendicitis: sonographic criteria based on 250 patients. Radiology 1988; $167: 327-9$.

17. Joshi Hol, patel VB, Dave AN. Ultrasonographic evaluation of Acute appendicitis. Ind J Radiology 1996; 2:75-8.

18. Ida chan, Simon G. Bicknell, Mary Graham, utility and Diagnostic Accuracy of sonography in detecting Appendicitis in a Community Hospital. AJR 2005; 184:1809-12.

19. Michael Rioux. Sonographic detection of normal and abnormal appendix. AJR 1992; 158:773-8.

20. Tarjan Z, mako E, Winternitz T et al. The value of ultrasonic diagnosis in acute appendicitis. Orv Hetil 1995; 136:713-7.

21. Lee SL, Walsh AJ, HO HS. Computed tomography and ultrasonography do not improve and may delay the diagnosis and treatment of acute appendicitis. Arch surg 2001; 136:556-62.

22. Hahn HB, Hoepna FV, Kalle et al. sonography of acute appendicitis in children-7 years' experience. paediatric Radiol 1998; 28:147-51.

23. Skanne P, Amiand PF, Nordshus T et al. Ultrasonography in patients with suspected appendicitis. A prospective study. Br Jr Radiol 1990; 63:787-93. 